\title{
VIDEOCLIPE E GÊNERO POR MEIO DE CONCEITOS DA COMUNICAÇÃO AUDIOVISUAL
}

\author{
Rodrigo Oliva ${ }^{1}$ \\ Tiago Signorini ${ }^{2}$ \\ Ana Maria Oliveira Leite Silva ${ }^{3}$ \\ Renata Bianca Ferreira ${ }^{4}$ \\ Jessy Laurie Pronçate Silva ${ }^{5}$ \\ Leandro Marcomini da Silva ${ }^{6}$
}

OLIVA, R.; SIGNORINI, T.; SILVA, A. M. O. L.; FERREIRA, R. B.; SILVA, J. L. P.; SILVA, L. M. da. Videoclipe e gênero por meio de conceito da comunicação audiovisual. EDUCERE - Revista da Educação, Umuarama v. 17, n. 1, p. 23-32, jan./jun. 2017

RESUMO: Este artigo discute a articulação da linguagem do videoclipe com as representações de gênero. Apresenta um estudo sobre algumas caracterizações dos conceitos da linguagem audiovisual, principalmente os estabelecidos a partir das configurações sonoras e imagéticas. Para a análise dos videoclipes, o estudo se atém ao escritos de Arlindo Machado, traçando um diálogo com os textos de Laura Mulvey, que representa os debates voltados às discussões temáticas de gênero.

PALAVRAS-CHAVE: Cinema; Comunicação; Linguagem; Vídeoclipe.

\section{VIDEOCLIPE AND GENDER BY CONCEPTS OF AUDIOVISUAL COMMUNICATION}

\footnotetext{
ABSTRACT: This article discusses the articulation of language of the music videos with the representations of genre. It presents a study about

DOI: https://doi.org/10.25110/educere.v17i1.2017.6280

${ }^{1}$ Doutor em Comunicação e Linguagens pela Universidade Tuiuti do Paraná. Professor e Pesquisador do curso de Publicidade e Propaganda da Universidade Paranaense.

E-mail: prof.rodrigo.oliva@gmail.com

${ }^{2}$ Acadêmico do Projeto de Iniciação Científica da Universidade Paranaense.

${ }^{3}$ Acadêmica do Projeto de Iniciação Científica da Universidade Paranaense.

${ }^{4}$ Acadêmica do Projeto de Iniciação Científica da Universidade Paranaense.

${ }^{5}$ Acadêmica do Projeto de Iniciação Científica da Universidade Paranaense.

${ }^{6}$ Acadêmico do Projeto de Iniciação Científica da Universidade Paranaense.
} 
some characterizations of the concepts of the audiovisual language, mainly those established from the sound and image configurations. For the analysis of the music videos, the study adheres to the writings of Arlindo Machado, drawing a dialogue with the texts of Laura Mulvey, that represents the debates directed to the thematic discussions of gender.

KEYWORDS: Cinema; Communication; Language; Music video.

\section{VIDEOCLIP Y GÉNERO A TRAVÉS DE CONCEPTOS DE COMUNICACIÓN AUDIOVISUAL}

RESUMEN: En esta investigación se ha discutido la articulación de lenguaje del videoclip con las representaciones de género. Se presenta un estudio sobre algunas caracterizaciones de conceptos del lenguaje audiovisual, principalmente los establecidos a partir de configuraciones sonoras y de imágenes. Para el análisis de los videoclips, el estudio se atiene a los escritos de Arlindo Machado, dibujando un diálogo con los textos de Laura Mulvey, que representan los debates vueltos a las discusiones temáticas de género.

PALABRAS CLAVE: Cine; Comunicación; Lenguaje; Videoclip.

\section{INTRODUÇÃO}

As pesquisas na área da comunicação encontram-se em amplo diálogo com outros ramos do conhecimento. Pensar em modelos metodológicos para desenvolver argumentos sobre assuntos, produção ou mesmo discussão dos elementos tradicionais do processo da comunicação requer uma compreensão de variadas abordagens transdisciplinares.

Entender a linguagem do videoclipe, como modelo de uma estrutura de linguagem contemporânea tornou-se o fundamento principal deste artigo. Já que o videoclipe foi pensado como um objeto para as diferentes análises que integravam debates e discussões feitas por meio de estudos. É notável, como aponta autores como Arlindo Machado (2000), a evidente influência da linguagem do videoclipe na contemporaneidade, pois trata-se de uma ampla variedade de experiências audiovisuais, bastante inovadoras que promovem debates e um intenso diálogo com os jovens.

As discussões de gênero tornaram-se importantes, pois foi por meio do olhar estabelecido para esse recorte que pode-se estabelecer al- 
gumas ideias. Percebe-se um intenso trabalho de artistas e músicos, no sentido, de apresentar debates sobre a cultura da representação do gênero e suas representações. Porém, o foco dessa reflexão não se atém ao debate dos pontos conceituais do gênero e sim, revela como as teorias da comunicação podem discutir videoclipes, cujo foco são as representações híbridas do gênero.

Portanto, serão apresentados neste trabalho, quatro recortes. Foram estabelecidas relações com a teoria queer do cinema, com a semiótica peircena, com a discussão dos olhares proposta por Laura Muvey (teoria feminista) e a experiências da composição do movimento cinematográfico. Metodologicamente, primeiramente, temos a identificação do videoclipe analisado, suas relações com o tema proposto, revelado pela cultura das representações de gênero. Em seguida, um desenvolvimento de análise por meio de uma conversa com as quatro teorizações relacionadas aos estudos da comunicação e suas variadas abrangências.

\section{PERFORMANCES SUBVERSIVAS - GÊNEROS HÍBRIDOS}

A ideia de gênero vem sendo estudada e apontada como um campo de possíveis articulações com os estudos audiovisuais. Segundo Robert Stam (2003, p. 289), a teoria queer do cinema promove a substituição da ideia binária de gêneros definidas pela masculinidade e feminilidade para uma construção social moldada pela relação híbrida entre os gêneros. Na linguagem do videoclipe, um dos componentes característicos é a apresentação coreográfica, que recria ritmo e visualidade. Percebe-se que tais apresentações são performáticas e sustentadas pela representação do corpo.

O videoclipe Touch me (2013), dirigido por Hindrek Maasik tem como característica principal o fato da representação se estabelecer por meio de aspectos coreográficos. Formado por um trio de bailarinos, o grupo Kazaky projeta, em todos os seus trabalhos, aspectos que revelam inclinações para uma subversão de gêneros, pois simbolizam imagens andróginas cujas representações de masculinidade e feminilidade são apresentadas simultaneamente. Segundo Dorotea Bastos (2012), as representações que marcam a musicalidade coreografada pode ser definida como "choreocinema". O termo é apresentado com uma representação 
que mescla dança e filme, sendo "choreo + cinema". Portanto, a adição dos termos sugere-se a ideia de um cinema focalizado no movimento do corpo humano.

Percebe-se que o videoclipe Touch me possui fragmentos do coreocinema e signos que interpretam algumas dessas representações, que subvertem o gênero. A mais representativa é a explosão do corpo dos bailarinos fixados em saltos altos. Um outro aspectos importante é que o videoclipe acontece num aeroporto, um espaço público, com funcionários pelos corredores e portões. A entrada do grupo no filme é séria, com postura e comando demonstrando poder da situação. Apesar da banda apresentar uma interpretação sensual visando os trejeitos e comportamento femininos, eles inserem mulheres no vídeo como veneradoras de suas performances e comportamentos. Percebe-se que as representações do corpo em suas performances exploram uma ação intermediadora. Segundo Wilton Garcia (2005, p. 123), a performance é compartilhada como uma prática de espetacularização do corpo, que torna-se automaticamente sujeito e objeto.

No cenário atual, videoclipes utilizam de diferentes recursos expressivos para dar sustento a ideias, padrões e movimentos desejados pelos idealizadores. A subversão dos gêneros no videoclipe Touch Me do grupo Kazaky é mantida pela ideologia do grupo. Percebe-se o jogo de representação da virilidade sobre o salto alto. Portanto, as representações no videoclipe Touch me criam um outro status, não feminino, não masculino, uma mistura que promove um debate de subversão de gêneros, marcados pelos elementos coreográficos e visuais da linguagem do videoclipe e do cinema.

\section{A ABORDAGEM SEMIÓTICA - REVELANDO A PRIMEIRIDA- DE}

$\mathrm{O}$ videoclipe constrói sintagmas elípticos e uma montagem rápida de fragmentos dispersos (MACHADO, 2000, p. 181), sugerindo uma narrativa em pleno desenvolvimento. Particularmente a linguagem do videoclipe se articula em códigos não específicos. É difícil encontrar elementos significantes próprios à linguagem. Isso atesta, o caráter híbrido da linguagem videográfica (OLIVA, 2012, p.7). Neste contexto, a presen- 
ça de elementos simbólicos dentro do videoclipe, os signos, irão, de certa maneira, demonstrar algo. Para Santaella (1983, p. 58), o signo é uma coisa que representa outra coisa: seu objeto. Ele só pode funcionar como signo se carregar esse poder de representar, substituir uma coisa diferente dele. Um signo intenta representar, em parte, pelo menos, um objeto que é, portanto, num certo sentido, a causa ou determinante do signo, mesmo se o signo representar seu objeto falsamente.

O videoclipe "Un Sueño Bajo El Agua" da cantora Ana Carolina não apresenta uma narrativa formal, visto que o corte e a mudança de cenas estão presentes de maneira bastante considerável. $\mathrm{O}$ vídeo foi gravado e, é exposto (cenas, personagens, objetos) submerso na água, gerando uma premissa de um novo plano como concepção de ambiente. Os signos colocados neste videoclipe geram consequências ao pensamento de funcionalidade, de projeção, de diversidade, etc. Oliva (2012, p.11) propõe que o videoclipe está contextualizado no tempo da fragmentação e das associações livres à procura de sentidos meramente factuais ou extremamente ricos de referências. Segundo Peirce, nenhum signo, por si mesmo, pode ser absolutamente preciso, visto que a relação do signo com seu objeto (aquilo que o signo representa) é uma fonte de indefinição na extensão ou aplicabilidade do signo e a relação do signo com o interpretante (o efeito que o signo produz na mente que o interpreta) é uma fonte de indefinição na profundidade (poder conotativo) do signo (SANTAELLA, 1992, p.50). A primeiridade observada no videoclipe, alvo desta pesquisa, está amparada na questão em que, conforme Santaella (2002, p.125), ora o signo, se considerado o seu lado qualitativo, é um quali-signo (signo em si) e na sua relação com o objeto ele será um ícone.

$\mathrm{O}$ videoclipe em estudo aponta ser autorreferencial, dado que a própria cantora está em cena e ela é parte no conjunto da produção, fazendo assim referência a si própria. São signos presentes no videoclipe analisado: a água, como referência ao movimento, mudança, criação; as mãos, como fonte de união e quebra de sentido; o relógio, pela conotação de tempo; o vestuário das personagens, como forma de gerar diversidade e possibilidade; anéis, representando o elo; guarda-chuva, demonstrando a diversidade expressa em suas cores.

Podemos concluir que o videoclipe em estudo é de caráter autorreferencial e parte dos elementos visuais se revela em sentido implícito. 
Os signos nele presentes não estão de maneira linear, mas apresentam projeções ligadas a seus objetos. Ainda, a primeiridade é observada, haja vista um padrão abstrato e um tanto subjetivo na relação signo, objeto e interpretante, ou seja, a possibilidade de se estabelecer relações de comparação, uma ação característica dos signos icônicos.

\section{COMPOSIÇÃO DO OLHAR}

O videoclipe se caracteriza por ser um formato audiovisual de curta duração, geralmente acompanhado pela música em sua totalidade. Arlindo Machado (2000) aponta que o objetivo principal de um videoclipe é transmitir uma mensagem, oferecer significados e identidade aos cantores e bandas. Levando em consideração tais aspectos, apresenta-se uma análise do videoclipe Blue Jeans (Yoann Lemoine, EUA, 2012), da cantora Lana Del Rey, cujo foco é compreender as várias representações do olhar.

Atualmente, a linguagem do videoclipe permite considerações que não se limitam somente a produção de uma performance musical. "Do ponto de vista prático, o videoclipe é um formato enxuto e concentrado, de curta duração e com um amplo potencial de distribuição" (MACHADO, 2005, p. 173). Segundo Laura Mulvey (1983) um filme oferece um número de prazeres possíveis, um deles é a escopofilia. A autora discute que: "há circunstâncias nas quais o próprio ato de olhar já é uma fonte de prazer, da mesma forma que, inversamente, existe prazer em ser olhado" (1983, p. 440). Ao transpor esta citação para a análise do videoclipe Blue Jeans, percebemos que há uma ideia de escopofilia diante dos olhares de desejo e ao mesmo tempo de medo que a personagem nos mostra no decorrer das cenas. A cantora Lana Del Rey é representada de forma que revela estar seduzida pelo olhar de Bradley, ator e modelo com quem ela protagoniza. Nesta cena, Bradley despe-se para um banho de piscina, enquanto Lana observa-o paralisada, o recurso utilizado na composição cênica é a sobreposição de imagens. Em um jogo de olhares erotizados, Bradley retribui o olhar para Lana.

Mulvey (1983) também ressalta que existem três séries diferentes de olhares associados ao fílmico: o da câmera que registra o acontecimento; o que se dirige à plateia e aqueles dos personagens dentro da ilusão da 
tela (1983, p. 452). Analisamos que este último representa esse jogo de olhares entre os personagens. No videoclipe, na cena inicial e filmada em primeiro plano, Lana fixa seu olhar para a câmera, denota-se que a projeção do olhar é para o receptor. Em outros momentos, o olhar se manifesta nas representações diretamente para a câmera, neste caso não se enxerga uma projeção que extrapola o limite da tela.

Segundo Arlindo Machado, o conceito de paralipse definido como omissão voluntária está associado ao olhar de personagens, assim "cria uma zona de mistério, um terreno de incertezas que a instância vidente pode trabalhar para produzir o famoso suspense emocional" (2007, p. 46). Observamos que o diretor do videoclipe utiliza este elemento na cena em que Lana se aproxima de Bladley. Nesse jogo de olhares, Bradley, ao ser comparado à figura de um crocodilo, transforma a representação de Lana em uma presa, o que promove uma ideia de peculiaridade e surpresa.

Portanto, nota-se que o videoclipe Blue Jeans, da cantora Lana Del Rey permite uma discussão sobre as várias composições de olhares que podem ser verificadas nos audiovisuais. Ao retratar esta relação, debatemos a ideia da autora Laura Mulvey (1983) que sistematizou três tipos de olhares em narrativas cinematográficas. Traçamos uma analogia desta teoria com a linguagem do videoclipe. Concluímos que na composição filmica de Blue Jeans, as tipologias de olhares, apontadas por Mulvey, foram encontradas.

\section{O RETARDAMENTO DA CÂMERA COMO EXPRESSÃO ESTÉ- TICA}

$\mathrm{Na}$ linguagem audiovisual, alguns recursos são utilizados de maneira a criar efeitos de aceleramento e retardamento da imagem. A câmera lenta é um destes recursos técnicos e pode ser encontrada em diversos videoclipes. Para Machado (2000, p.178), os videoclipes são interessantes a partir do momento em que nota-se que sua criação nasce de uma sensibilidade renovada e de uma decisão crítica na interconexão entre planos musicais e visuais. O diretor israelense Roy Raz utiliza-se da câmera lenta em seu videoclipe "The Lady Is Dead" (Israel, 2011), cujo recurso pode ser visível em toda a narrativa do videoclipe. 
No texto Cinema: o uso criativo da realidade, Maya Deren aponta que a câmera lenta pode ser uma afirmação tanto de estado ideal ou incômoda frustação, um tipo de meditação íntima e amorosa num movimento ou uma solenidade que acrescenta ritual a uma ação (DEREN, 2012, p.143). No videoclipe “The Lady Is Dead", percebe-se que o diretor Roy Raz aplica o recurso da câmera lenta desde a primeira cena, quando traz uma bailarina ao lado de um piano. Nota-se que ao usar de tal recurso, os personagens são valorizados numa performance desnaturalizada, o que aponta uma reflexão sobre o uso criativo da realidade, já que esta é mostrada de uma forma diferenciada daquela que normalmente se apresenta ao nosso olhar. Em outra cena, três rapazes são mostrados sem roupas, valorizando a composição do corpo nu. Em seguida, o diretor Roy Raz evidencia mais a questão da representação do corpo, quando traz em cena, vários homens seminus lavando um automóvel e utilizando novamente o recurso da câmera lenta. No texto: "A Inteligência de uma máquina", publicado em 1946, Jean Epstein (In XAVIER, 1983, p. 292) discutiu que a utilização do recurso da câmera lenta na imagem cinematográfica transformava a representação realista dos personagens em uma representação sem vitalidade, como se os personagens diminuíssem a mobilidade em gestos e transformassem em matérias vivas, porém sem pensamentos como se não tivessem vida.

No videoclipe analisado, os personagens se aproximam de um estágio de representação cuja projeção evoca uma ideia de animalidade. Sendo assim, ao utilizar o recurso da câmera lenta, na abordagem estética, valoriza-se o caráter de que as performances dos personagens no videoclipe apresentam-se como matéria pura sem traços de espiritualidade.

Portanto, percebe-se que o uso da câmera lenta na linguagem audiovisual desenvolve uma percepção de que as performances dos personagens são desnaturalizadas. Sendo assim, por meio de uma reflexão dos movimentos apresentados no videoclipe "The Lady is dead", conclui-se que o diretor Roy Raz utiliza-se da estratégia do recurso da câmera lenta, que destaca a perda do caráter realista na expressão dos personagens.

\section{CONSIDERAÇÕES FINAIS}

Neste artigo foi possível observar vários vieses que podem ser 
utilizados para o desenvolvimento de uma pesquisa na área da comunicação. Foram estabelecidas relações entre contextos teóricos, produção audiovisual e abordagens específicas relacionadas às representações de gênero.

O videoclipe é considerado um gênero de produção audiovisual impactante e que vem nos últimos tempos, não somente, projetando a imagem de cantores de natureza pop, mas também por meio de representações, discutindo questões pontuais do discurso dos gêneros e signos.

Atestamos a importância deste entrecruzamento dos campos do saber, pois como foi percebido, em cada uma das abordagens as discussões tornam-se eficientes a partir do diálogo que estabelecem entre as variadas camadas do conhecimento.

Finaliza-se esse trabalho reforçando que seu fundamento metodológico se atém ao debate, que visa à escolha de um objeto, as potencialidades do recorte e o estabelecimento de um diálogo com uma teorização. Estas relações tem o fundamento primordial de revelar a produção de ideias e promoção de saberes

\section{REFERÊNCIAS}

ANA, C. Un sueño bajo el agua. Disponível em: <http://www.youtube. com/watch? $\mathrm{v}=$ ozBoy8R6aLY>. Acesso em: 10 ago. 2014.

BASTOS, D. Coreocinema: Maya Daren e o cinema experimental de dança. In: BLUE Jeans, 14., Direção Yoann Lenoine. Oualid Mouaness Production. 2012. 1 filme (4min21seg.), son., color.

CONGRESSO DE CIÊNCIAS DA COMUNICAÇÃO NA REGIÃO NORDESTE. Recife, 2012. Anais... Recife: Intercom, 2012.

DEREN, M. Cinema: o uso criativo da realidade. Devires, Belo Horizonte, v. 9, n. 1, p.128-149, jan./jun. 2012. Disponível em: <http:// www.fafich.ufmg.br/ devires/v9n1/download/08-maya.pdf $>$. Acesso em: 01 ago. 2014.

EPSTEN. J. A inteligência de uma máquina. In: XAVIER, I. A experiência do cinema. Rio de Janeiro: Graal, 1983. 
GARCIA, W. Corpo, mídia e representação. São Paulo: Pioneira Thonson Learning, 2005.

KAZAKY. Touch me. Disponível em: <https://www.youtube.com/ watch?v=4Cm9jZPQ_Cw>. Acesso em: 12 ago. 2014.

THE LADY is dead. Direção Roy Raz. Roy Raz and Eitan Tal Producers. 2011. 1 filme (4min39seg.), son., color.

MACHADO, A. A televisão levada a sério. São Paulo: SENAC, 2000.

. A. O sujeito na tela: modos de enunciação no cinema e no ciberespaço. São Paulo: Paulus, 2007.

MULVEY, L. Prazer visual e cinema narrativo. In: XAVIER, I. A experiência do cinema. Rio de Janeiro: Edições Graal, 1983.

OLIVA, R. Discurso em Turbulência: um olhar para o videoclipe em contexto intertextual. In: CONGRESSO DE CIÊNCIAS DA COMUNICAÇÃO NA REGIÃO SUL, 13., 2012, Chapecó. Anais... Chapecó: Intercon, 2012.

SANTAELLA, M. L. O que é semiótica. São Paulo: Brasiliense, 1983. . A assinatura das coisas. Rio de Janeiro: Imago, 1992. . Semiótica aplicada. São Paulo: Thomson, 2002.

STAM, R. Introdução à teoria do cinema. Campinas: Papirus, 2003.

Recebido em: 26/01/2017

Aprovado em: 22/03/2017 